University of Rhode Island

DigitalCommons@URI

Open Access Master's Theses

1993

\title{
Latent Transition Analysis for the Stages of Change
}

Rosemarie A. Martin

University of Rhode Island

Follow this and additional works at: https://digitalcommons.uri.edu/theses

\section{Recommended Citation}

Martin, Rosemarie A., "Latent Transition Analysis for the Stages of Change" (1993). Open Access Master's Theses. Paper 1651.

https://digitalcommons.uri.edu/theses/1651

This Thesis is brought to you for free and open access by DigitalCommons@URI. It has been accepted for inclusion in Open Access Master's Theses by an authorized administrator of DigitalCommons@URI. For more information, please contact digitalcommons-group@uri.edu. 


\begin{abstract}
The transtheoretical model of behavior change proposes that in an effort to change behavior people progress through a number of stages, beginning with precontemplation, through contemplation, action and maintenance. This study is an application of latent transition analysis (LTA) to movement through the stages of change for smoking cessation. LTA is an extension of latent class theory and Markov modeling that examines change over time. The sample consisted of 545 reactively recruited smokers and former smokers with a mean $( \pm S D)$ age of $39.7(12.0)$ years. Of the sample, $68 \%$ were female and $94.7 \%$ were white. Stage membership was assessed five times over a two year period using a stage classification algorithm.

LTA was used to compare three specified models of movement among the four stages of change over the five time periods. Model I proposes only one stage forward movement. Model II proposes both forward and backward movement of one stage only. Model III proposes both one stage forward and backward movement and allows two stage forward movement. Goodness-of-fit chi-square tests revealed that Model III represented the data best. This result indicates that both progression and regression among the stages takes place as well as two stage progression.

Examination of the probability of movement among the stages revealed three findings consistent with the transtheoretical model. First, movement through the stages is not always linear. Second, the probability of forward movement was greater than backward movement. Third, the probability of moving to adjacent stages was greater than the probability of two stage progression.
\end{abstract}




\section{ACKNOWLEDGEMENTS}

I would like to thank all of the members of my thesis committee. I appreciate their helpful comments and feedback. I extend sincere thanks to Joe Fava who provided invaluable technical assistance in getting the software needed for this study up and running. Joe's knowledge of fortran saved much time and effort on my part. I cannot thank him enough.

I especially thank Wayne Velicer. Wayne's high standards and acumen have been an inspiration for this project and all other graduate school endeavors. I am grateful for the opportunity to work with a major professor of his merit.

I would also like to thank Linda $\mathrm{M}$. Collins who provided the software, the user's manual for the latent transition analysis program and technical support. Her clarifications, explanations and suggestions helped in figuring out the subtleties of running the program.

Finally, I am indebted to my husband, Bruce, and my parents, Roger and Lorraine Martin, for their incessant encouragement and support. I dedicate this project to Jennie and Brandon, whose love and appreciation for life helped maintain my sense of perspective. 


\section{TABLE OF CONTENTS}

page

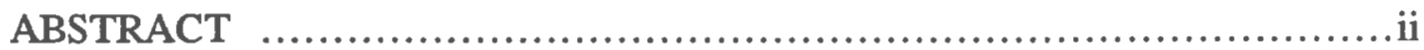

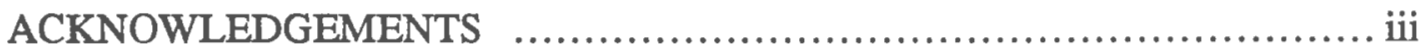

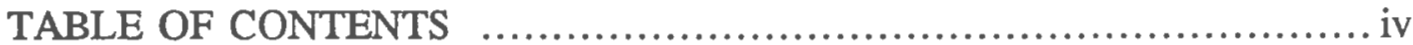

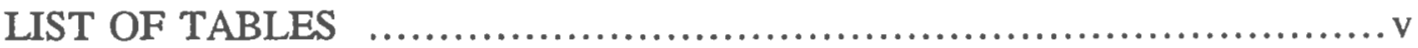

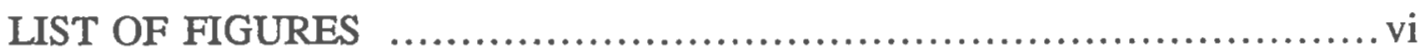

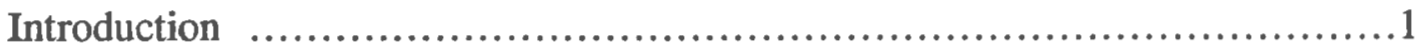

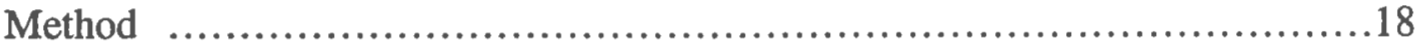

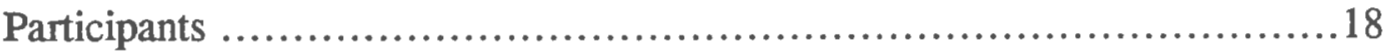

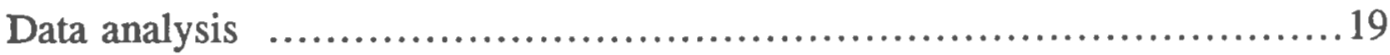

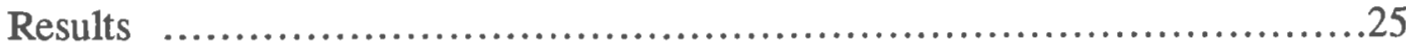

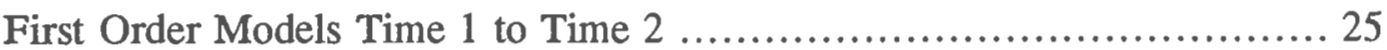

First Order Models Time 2 to Time 3 ................................... 32

First Order Models Time 3 to Time 4 ................................. 35

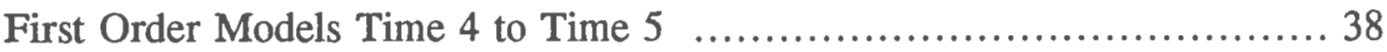

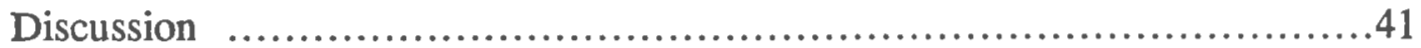

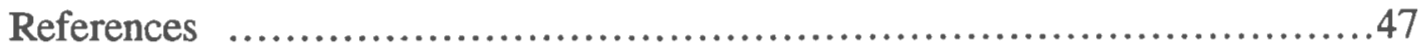

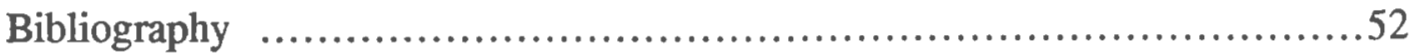




\section{LIST OF TABLES}

page

Table 1

Delta Parameter Estimates, Probabilities of Latent Status Membership,

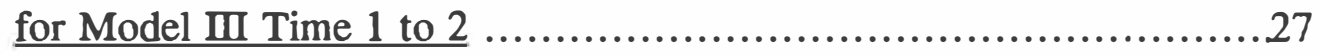

Table 2

Tau Parameter Estimates, Probabilities of Latent Status Transitions.

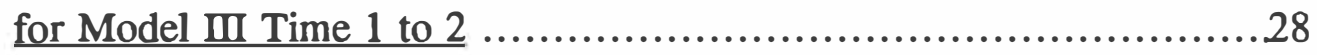




\section{LIST OF FIGURES}

page

Figure 1

Model I: One Stage Forward Movement Only

Figure 2

Model II: One Stage Forward and Backward Movement 21

Figure 3

Model III: One Stage Forward and Backward Movement

and two stage forward movement

Figure 4

Tau Parameter Estimates for Model III Time 1 to 2 30

Figure 5

Tau Parameter Estimates for Model III Time 2 to 3

Figure 6

Tau Parameter Estimates for Model III Time 3 to 4 37

Figure 7

Tau Parameter Estimates for Model III Time 4 to 5 40 


\section{LATENT TRANSITION ANALYSIS FOR THE STAGES OF CHANGE}

The Transtheoretical Model of Behavior Change is a general model which has been applied extensively in the area of health related behaviors. Changing problem behaviors does not occur rapidly or automatically. The model maintains that behavior change is not a dichotomous event in which people shift from unhealthy behavior to healthy behavior, but rather a sequence of small changes, both cognitive and behavioral, which people move through in their efforts to change a behavior. The Transtheoretical Model is a three dimensional model for looking at change that combines stages of change, a temporal ordering, independent variables, including the processes of change (Prochaska, Velicer, DiClemente \& Fava, 1988) and dependent variables like the pros and cons (Velicer, DiClemente, Prochaska \& Brandenburg, 1985) from decisional balance, self-efficacy and temptation (Velicer, DiClemente, Rossi \& Prochaska, 1990), and outcome behaviors specific to the problem (Prochaska \& DiClemente, 1983; DiClemente, Prochaska, Fairhurst, Velicer, Velasquez \& Rossi, 1991; Velicer, Prochaska, Rossi \& Snow, 1992). The focus of this paper, however, will be strictly on the stages of change.

The framework of the Transtheoretical Model was developed from an investigation of how change process activities could be measured in psychotherapy. The goal was to identify common elements across different approaches to psychotherapy. Prochaska and DiClemente (1983) combined the processes of change with stages of change. They found that process use varied by stage. It is the stage by process relation, the stage by dependent measures relation and the process by 
dependent measure relation that remains the focus of the transtheoretical model research.

Smoking cessation has been the most widely investigated problem area (Prochaska \& DiClemente, 1983, 1984, 1986). The literature on smoking cessation and the stages of change is extensive and has been replicated repeatedly. The model has been applied to other cessation areas such as alcohol and drugs. More recently, the model has been applied to the acquisition of health promoting behaviors such as nutrition, exercise, safe sex, and medical compliance.

Change involves progression through a series of stages. The stages of change are redefined within the context of each problem area. DiClemente \& Prochaska (1982) first developed the theoretical framework for the stages of change by examining smoking cessation. By comparing self-changers versus smokers engaged in commercial treatment programs, five common stages of change were identified for both self-chargers and therapy changers (DiClemente \& Prochaska, 1982). These stages were identified as precontemplation, contemplation, determination, action, and maintenance. McConnaughy, Prochaska, and Velicer (1983) developed a method for measuring the stages discretely using a 5-item algorithm or continuously using a 32item questionnaire. They found four reliable components. The results for the middle stage, determination, were not consistent and therefore only four stages were worked with for seven years. A fifth stage, reconceptualized as preparation, was incorporated into the model in an analysis of the process of smoking cessation (DiClemente et al., 1991; Velicer et al., 1992). 
The stages of change has utility since it divides a population into mutually exclusive categories. One method of measuring the stages results in an ordered categorical variable with five categories. There are several prominent stage theories within psychology such as Piaget's stages of cognitive development, Kohlberg's stages of moral development (Kohlberg, 1969), and Kubler-Ross's stages for coping with death (Kubler-Ross, 1975). Although there are stage theories, procedures for adequately analyzing qualitative stage variables have been limited. Recently, Collins, Wugalter and Rousculp (1991) developed latent transition analysis for use with stage sequential dynamic latent variables. The purpose of this study is to examine movement among the stages of change over time using latent transition analysis (Collins, Wugalter \& Rousculp, 1991).

This paper will discuss the characteristics of the stages of change and the dynamic relationship among the stages. A brief overview of latent class theory is provided as it is the foundation of latent transition analysis. An in depth discussion of latent transition analysis is presented along with applications of latent transition analysis. Lastly, an example of latent transition analysis to the stages of change for smoking cessation is provided.

\section{Stages of Change}

Precontemplation. Precontemplation is the earliest of the stages of change. People in precontemplation are not seriously thinking of changing their problem behavior in the next six months. The six month time frame is used because this is about how much in the future people plan to change their behavior (Velicer et al., 
1992). People may be in the precontemplation stage because they are demoralized about their abilities to change, they are uninformed or under informed about the risk of their behavior, or they are defensive about their behavior (Prochaska \& Goldstein, in press).

Contemplation. Contemplators are those people who are seriously thinking about changing their behavior in the next six months. They are not prepared to take action at present, but are considering the possibility and the consequences of change (Velicer et al., 1992).

Preparation. Preparation is the ready-for-action stage. Here, individuals have intentions of changing smoking within a month. They also engage in small but deliberate steps toward action. Examples of small steps taken by smokers are given by Prochaska and Goldstein (in press): they delay their first cigarette of the day, they smoke less cigarettes when compared with contemplators and precontemplators, and have tried to quit more often.

Action. Action is marked by the overt modification of behavior. The six month action stage is also the stage with the greatest risk for relapse of the behavior change. Awareness of the possible lapses and slips and awareness of strategies for relapse prevention are of importance to action.

Maintenance. Maintenance is the final stage and spans the time period from action to when the change is complete and no chance of relapse exists. Maintenance can be jeopardized by environmental and internal cues that trigger the old behavior. Maintenance is different from termination of smoking behavior in that during 
maintenance there is continued change. Termination is a more static time period (Velicer et al., 1992). Not all behavior change will result in termination.

\section{Movement Among Stages}

Progression through the stages of change usually is not linear. Regression is the general term used for any return from an advanced stage to an earlier stage. Relapse is marked by an event that terminates the action stage (DiClemente et al., 1991). Prochaska and DiClemente (1992), for example, followed 1,000 self-changers for two years and found that it takes an average of three to four cycles through the stages before an individual is completely free from smoking, with relapse being the rule rather than the exception. Only $5 \%$ of 200 contemplators progressed to maintenance without relapse. Of those individuals that do relapse, they found that only $15 \%$ give up and $85 \%$ recycle back to take further action.

\section{Measuring the Stages of Change}

The stages of change have been measured by several methods. The critical elements to measure are intentions and behaviors specific to each stage and each problem behavior (DiClemente et al., 1991). The two most widely used methods to assess stage of change are the University of Rhode Island Change Assessment Scale (URICA) and classification algorithms. The URICA consists of 32 items that reveal four subscale scores for precontemplation, contemplation, action, and maintenance (McConnaughy, Velicer, \& Prochaska, 1983). These results have been replicated (McConnaughy, DiClemente, Prochaska, \& Velicer, 1989).

A categorical classification system based on five questions and an algorithm 
based on the responses has been developed. This is the most extensively employed method of measuring stage membership. The five questions for smoking cessation are as follows: 1) "Are you currently smoking?, 2) Are you seriously considering quitting in the next 6 months?, 3) Are you planning to quit in the next 30 days?, 4) Have you quit smoking for a period of at least 24 hours in the past year?, and 5) How long have you been off cigarettes?" (Prochaska \& DiClemente, 1992, p.11). Additional items are typically included to verify the responses to these key questions. Following the algorithm, individuals in precontemplation are smoking and are not seriously considering changing in the next six months. Contemplation includes smokers who are seriously considering quitting in the next six months. Smokers in the preparation stage are those who both are intending to quit in the next 30 days and have quit smoking for at least 24 hours in the past year. People in action are those who currently do not smoke and have quit within the last six months. Those who have quit smoking for more than six months are classified as being in the maintenance stage.

\section{Latent Transition Analysis}

Psychology has long been concerned with measuring individual growth and development over time. Often, the focus of study is a variable or construct that is not directly observable. These constructs called latent variables are either static or dynamic (Collins \& Cliff, 1990). Several measurement theories are used for continuous, quantitative latent variables (Fisher, 1983; Embretson, 1991; Collins and Cliff, 1990). Much behavior, however, is characterized not as continuous measures 
but as discrete stages, or latent statuses, that qualitatively represents where an individual is in a growth or development process. Such stage theories are abundant in the psychological literature. Until recently the methodology for examining qualitative latent variables was not available.

Markov models, used to predict the probability of movement through stages over a specific time interval, are the most widely employed measurement technique for dealing with discontinuous variables. Markov models, however, do not permit measurement error, and may, therefore, not truly reflect a data set. Latent class theory is a method for looking at stage sequential latent variables that allows for measurement error. By combining Markov models and latent class theory, measurement uncertainty can be incorporated into the model (Wiggins, 1973; Lazarfeld \& Henry, 1968). Several methods of parameter estimation for this approach have been developed (Bye and Schechter, 1986; van de Pol and de Leeuw, 1986; van de Pol and Langeheine, 1989).

Latent class measurement theory (Clogg \& Goodman, 1984; Dayton \& Macready, 1976; Lazarfeld \& Henry, 1968) is grounded by discontinuous latent variables measured by responses to an instrument. Items are usually dichotomous and are manifest indicators of the latent variable. Latent class membership, defined by the latent variable, is mutually exclusive, and all members of a population are classified into one latent class. Latent class theory is limited, however, because it does not handle dynamic latent variables that change systematically over time (Graham, Collins, Wugalter, Chung \& Hansen, 1991). 
Latent transition analysis extends LCT to include latent status measured by · dynamic latent variables, and also examines movement among the latent statuses over time. As with LCT, LTA contains parameters that represent the possible error of the manifest items. Latent Class is measured only once and does not change, i.e., gender or treatment condition. In contrast, Latent Status is measured a minimum of two occasions and is expected to change over time.

The stages of change model involves five latent statuses which are: (1) precontemplation (PC); (2) contemplation (C); (3) preparation (P); (4) action (A); and (5) maintenance (M). At any time a smoker is in one of these latent statuses or stages. The transition probability matrix represents movement from one stage to another at each occasion of measurement. The individual probability are represented as $\tau_{\mathrm{B} \mid \mathrm{A}}$ where $\tau$ is a probability, i.e., $0 \leq \tau \leq 1.00$, and $\mathrm{A}$ is the latent status at time 1 and $B$ is the latent status at time 2. Since movement among stages can be either forward or backwards, there is a full probability matrix. If we assume two occasions of measurement and no latent class variable, the transition $5 \mathrm{X} 5$ probability matrix for the stages of change would be represented as:

Occasion 2

$$
\begin{array}{lllll}
\tau_{\mathrm{PC} \mid \mathrm{PC}} & \tau_{\mathrm{C} \mid \mathrm{PC}} & \tau_{\mathrm{P} \mid \mathrm{PC}} & \tau_{\mathrm{A} \mid \mathrm{PC}} & \tau_{\mathrm{M} \mid \mathrm{PC}} \\
\tau_{\mathrm{PC} \mid \mathrm{C}} & \tau_{\mathrm{C} \mid \mathrm{C}} & \tau_{\mathrm{P} \mid \mathrm{C}} & \tau_{\mathrm{A} \mid \mathrm{C}} & \tau_{\mathrm{M} \mid \mathrm{C}}
\end{array}
$$

[1] Occasion 1

$$
\begin{array}{llllll}
\tau_{\mathrm{PC} \mid \mathrm{P}} & \tau_{\mathrm{C} \mid \mathrm{P}} & \tau_{\mathrm{P} \mid \mathrm{P}} & \tau_{\mathrm{A} \mid \mathrm{P}} & \tau_{\mathrm{M} \mid \mathrm{P}} & =\tau \\
\tau_{\mathrm{PC} \mid \mathrm{A}} & \tau_{\mathrm{C} \mid \mathrm{A}} & \tau_{\mathrm{P} \mid \mathrm{A}} & \tau_{\mathrm{A} \mid \mathrm{A}} & \tau_{\mathrm{M} \mid \mathrm{A}} & \\
\tau_{\mathrm{PC} \mid \mathrm{M}} & \tau_{\mathrm{C} \mid \mathrm{M}} & \tau_{\mathrm{P} \mid \mathrm{M}} & \tau_{\mathrm{A} \mid \mathrm{M}} & \tau_{\mathrm{M} \mid \mathrm{M}} &
\end{array}
$$

where $\tau_{\mathrm{PC} \mid \mathrm{PC}}$ is the probability of membership in the precontemplation stage on the 
second occasion conditional upon membership in the precontemplation stage on the first occasion. Likewise $\tau_{\mathrm{C} \mid \mathrm{A}}$ is the probability of membership in the contemplation stage on the second occasion conditional upon membership in the action stage on the first occasion. Since there is a time element involved in defining the stages of change some elements of the matrix could be fixed at zero depending on the time interval between the occasions of measurement. For example, if the two occasions of measurement are only four months apart, it is not possible to move from the contemplation stage to the maintenance stage since the action stage between them is defined as a six month period. Therefore, $\tau_{\mathrm{M} \mid \mathrm{C}}$ would be fixed at zero.

\section{The Latent Transition Analysis Model and Notation}

The model is most easily understood with a simple example. Assume there are two occasions of measurement, five latent statuses, and a static latent variable with two latent classes. The occasions of measurement will be define as time $t$ for the first and time $t+1$ for the second. Latent status represented by $S$, will be defined as PC (precontemplator) for the first latent status, $C$ (contemplator) for the second latent status, P (preparation) for the third latent status, A (action) for the fourth latent status and $\mathbf{M}$ (maintainer) for the final latent status. $\mathbf{S 1}$ will represent latent status at time 1 and S2 will represent latent status at time 2. Assume that latent status is measured by five items, item 1 , item 2 , item 3 , item 4 , and item 5 where $g, h, i, j, k$, equal responses at time $t$ and $g^{\prime}, h^{\prime}, i^{\prime}, j^{\prime}, k^{\prime}$ equal responses at time $t+1$. Lastly assume that latent class, type of change, self change or therapy assisted change, is measured by one item where $m$ equals the response to the item. Therefore, each participant will 
have a vector of response patterns $(Y)$ for each of the measured variables where $Y=\left\{m, g, h, i, j, k, g^{\prime}, h^{\prime}, i^{\prime}, j^{\prime}, k^{\prime}\right\}$.

LTA models involve four different types of parameters: [1] the gamma parameters $(\gamma)$, which are estimates of the proportion of the population in each latent class or subgroups, [2] the delta parameters $(\delta)$, which are estimates of the proportion of the population in each latent status at each occasion of measurement, [3] the tau parameters $(\tau)$ which refer to the probability of transitioning from one latent status to another, and [4] the rho parameters $(\rho)$, which represent measurement error, that are estimates of a particular item response conditional on latent status and latent class membership. The formal mathematical equation for the LTA model is represented by:

$[2] \gamma_{\mathrm{LC}} \rho_{\mathrm{M} \mid \mathrm{LC}} \delta_{\mathrm{S} \mid \mathrm{LC}} \rho_{\mathrm{g} \mid \mathrm{S} 1, \mathrm{LC}} \rho_{\mathrm{h} \mid \mathrm{S} 1, \mathrm{LC}} \rho_{\mathrm{i} \mid \mathrm{S} 1, \mathrm{LC}} \rho_{\mathrm{j} \mid \mathrm{S} 1, \mathrm{LC}} \rho_{\mathrm{k} \mid \mathrm{S} 1, \mathrm{LC}} \tau_{\mathrm{S} 2 \mid \mathrm{S} 1, \mathrm{LC}} \rho_{\mathrm{g}^{\prime} \mid \mathrm{S} 2, \mathrm{LC}} \rho_{\mathrm{h}^{\prime} \mid \mathrm{S} 2, \mathrm{LC}} \rho_{\mathrm{i}^{\prime} \mid \mathrm{S} 2, \mathrm{LC}}$ $\rho_{\mathrm{j}^{\prime} \mid \mathrm{S} 2, \mathrm{LC}} \rho_{\mathbf{k}^{\prime} \mid \mathrm{S} 2, \mathrm{LC}}$

The gamma parameters $\left(\gamma_{L C}\right)$ represent the proportion in each latent class. The gammas sum to one. The number of $\gamma$ 's estimated freely is $C-1$ where $C$ is the number of latent classes. An example of a latent class would be an experimental manipulation that would result in two or more latent classes or gender. These typically do not change across occasions of measurement. The present application of LTA to the stages of change for smoking cessation does not have a latent class variable. The data were gathered as part of naturalistic study that had no intervention. However, future studies could incorporate a latent class variable, such as intervention group or gender, to examine between group differences. This is particularly interesting for stage matched interventions. Participants who would 
receive staged matched interventions when compared with controls who did not receive stage matched interventions are expected to progress through the stages with higher probability. The LTA method could be used to examine these differences.

The delta parameters $\left(\delta_{\mathrm{S} \mid \mathrm{LC}}\right)$ are the proportion of the population in each of the five latent statuses at each occasion of measurement conditional on latent class. There is one delta for each latent status at each occasion of measurement. In this example the $\delta_{\mathrm{S} \mid \mathrm{LC}}$ is a vector.

$$
\delta_{\mathrm{S} \mid \mathrm{LC}}=\begin{aligned}
& \delta_{\mathrm{PC} \mid L C} \\
& \boldsymbol{\delta}_{\mathrm{C} \mid L C} \\
& \delta_{\mathrm{P} \mid L C} \\
& \boldsymbol{\delta}_{\mathrm{A} \mid L C} \\
& \delta_{\mathrm{M} \mid L C}
\end{aligned}
$$

Where $\delta_{\mathrm{PC} \mid L C}$ is the proportion in the precontemplation stage, $\delta_{\mathrm{C} \mid \mathrm{LC}}$ is the proportion in the contemplation stage, $\delta_{\mathrm{P} \mid \mathrm{LC}}$ is the proportion in the preparation stage, $\delta_{\mathrm{A} \mid \mathrm{LC}}$ is the proportion in the action stage, and $\delta_{\mathrm{M} \mid \mathrm{LC}}$ is the proportion in the maintenance stage. The number of freely estimated $\delta$ parameters is equal to $C(S-1)$, in this example 2(51) or 8. Examination of the delta parameters show the growth or decline in latent status membership over time.

The tau parameters $\left(\tau_{\mathrm{S} 2 \mid \mathrm{S} 1, \mathrm{LC}}\right)$ matrix is the transition probability matrix representing the probabilities of transitioning to each of the latent statuses at time 2 conditional upon membership in a particular latent status at time 1 and latent class. The $\tau$ 's form the transition probability matrix and is an $S \mathrm{X} S$ matrix. In this example the tau matrix is a $5 \times 5$ matrix (see [1]). There is one tau matrix for each occasion of measurement. The rows of the tau matrix sum to one. In a first order model the 
number of parameters estimated freely is equal to $S(S-1)(T-1)$ where $T$ is the number of occasions of measurement.

The diagonal elements of the tau matrix represent stability, i.e., the proportion of individuals who remain in the same latent status on both occasions of measurement. The elements above the diagonal represent progression. These values represent the proportion of individuals who move forward to a new latent status on the second occasion. The elements below the diagonal represent regression, i.e., the proportion of individuals who move backward to a previous latent status on the second occasion.

If there are three or more occasions of measurement the transitions among the latent statuses are conditional upon not only the most recent latent status membership but also on the latent status two occasions of measurement previous. All parameters for second-order models are a direct extension of the first-order model with the exception of the tau parameters. There are $C S(S-1)+C S^{2}(S-1)(T-2)$ possible tau parameters to be freely estimated in the second-order model.

There are two sets of rho parameters $(\rho)$; one associated with the static latent variable representing latent class membership and one associated with the dynamic latent variable representing latent status membership. The rho's $(\rho)$ represent the probability of a particular response to each manifest variable at each occasion of measurement conditional on latent class membership and/or latent status membership. The measurement parameters $\left(\rho_{\mathrm{M} \mid \mathrm{LC}}\right)$ represent the probability of responses to the item measuring the static latent variable conditional on latent class membership. In other words, what is the probability a member of latent class one will select the first 
response category. For example, for item 1 with two response categories, the following rho's would be found:

\begin{tabular}{|c|c|c|c|}
\hline LC1 & $\begin{array}{l}\text { Item 1 } \\
\rho_{1 \mid \mathrm{LCC}}\end{array}$ & LC1 & Item 1 \\
\hline LC2 & $\rho_{1 \mid \mathrm{LC} 2}$ & LC2 & $\rho_{2 \mid L C 2}$ \\
\hline
\end{tabular}

The rho parameters associated with the dynamic latent variable represent the probability of response to the item measuring the dynamic latent variable conditional on latent status membership and latent class membership. For our example assume that the five items measuring latent status are dichotomous, yes/no, items.

Latent Class 1, Time 1

Responses Category 1

IT1 IT2 IT3 IT4 IT5 IT1 IT2 IT3 IT4 IT5

[5] $\quad \rho_{\mathrm{g} \mid \mathrm{PC}, \mathrm{LC}} \rho_{\mathrm{b} \mid \mathrm{PC}, \mathrm{LC}} \rho_{\mathrm{i} \mid \mathrm{PC}, \mathrm{LC}} \rho_{\mathrm{j} \mid \mathrm{PC}, \mathrm{LC}} \rho_{\mathrm{k} \mid \mathrm{PC}, \mathrm{LC}} \quad \rho_{\mathrm{g} \mid \mathrm{PC}, \mathrm{LC}} \rho_{\mathrm{h} \mid \mathrm{PC}, \mathrm{LC}} \rho_{\mathrm{i} \mid \mathrm{PC}, \mathrm{LC}} \rho_{\mathrm{j} \mid \mathrm{PC}, \mathrm{LC}} \rho_{\mathrm{k} \mid \mathrm{PC}, \mathrm{LC}}$

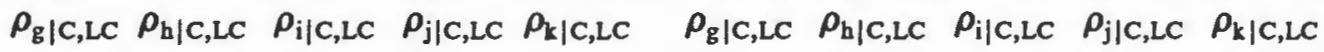

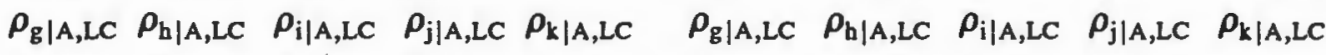

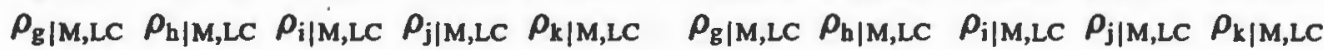

The elements of the rho matrix represent the probability that members in a particular stage and latent class will select a particular response category one. For example $\rho_{\mathrm{g} \mid \mathrm{PC}, \mathrm{LC}}$ represents the probability that members of the precontemplation stage that belong in latent class 1 will respond with category one, or yes, to first item measuring the dynamic latent variable.

The $\rho$ 's serve two roles in the LTA model. The $\rho$ 's map the manifest item onto the latent statuses as factor loadings show the relationship between items and a factor. And the $\rho$ 's also show how precisely the manifest items measure the latent variables. The rho parameters can be interpreted as representing the relationship 
between the manifest variables and latent classes in the same way the factor loadings relate the manifest variables to the latent factors in structural equation modeling. The values close to 0 or 1 indicate that the manifest response is determined by latent status membership and values that are close to one divided by the number of response patterns are determined by chance. The parameters associated with the latent class variable that can be estimated freely are $C I(R-1)$ where $R$ is the number of response categories for each manifest variables. The parameters associated with the latent status variable that can be estimated freely are $\operatorname{CSTJ}(M-1)$ where $M$ is the number of response categories for each manifest variable.

The present application to the stages of change will not focus on rho parameters. It is assumed that there is no measurement error in classification of stage membership. The present study had only one measure for latent status and verification measures were available and used in data cleaning to correct erroneous stage classification. However, use of the rho parameters in future studies could compare the classification algorithm used in this study to alternate measures of stage membership such as the URICA (McConnaughy, Prochaska \& Velicer, 1983; McConnaughy et al., 1989) and the contemplation ladder (Abrams, Emmons, Linnan \& Biener, in press).

\section{Estimation}

The LTA program (Collins et al., 1991) uses the EM algorithm (Dempster, Laird, \& Rubin, 1977) for estimating the four types of parameters. Collins and Wugalter (1992) conducted a study using artificial data to determine the ability of the 
EM algorithm to recover LTA model parameters and the ability of the procedure under varying conditions. Two models were used. One that allowed developmental reversals and the second model that did not. Two measurements strengths, weak and strong, were used. The number of items varied between three and six, and sample sizes were set at either 300 or 1000 . Good parameter recovery is marked by the parameter estimate being equal to the true parameter value with a small standard error. The results of the simulation study showed that parameter recovery was acceptable under a variety of conditions (Collins \& Wugalter, 1992).

LTA is used to determine how well a particular model fits the data. A model predicts the number of people who will contribute to a particular response pattern. A good fitting model will have predictions that are close to the actual data. The goodness of fit statistic will be small relative to degrees of freedom for a good fitting model (Graham et al., 1991). $G^{2}$, a likelihood-ratio goodness-of-fit statistic, is approximately distributed as a chi-square where degrees of freedom is equal to the number of response patterns minus the number of estimated parameters minus one or expressed $d f=K-P-1$. A model is considered identified when the number of . parameters estimated is less than the number of response patterns minus one. An additional criterion for assessing the fit of a model is a modified likelihood ratio statistic (Collins \& Wugalter, 1992). The Akaike Information Criterion (AIC) (Akaike, 1987) is $\mathrm{G}^{2}+2 p$, where $p$ is the number of parameters estimated. 


\section{Examples}

LTA has been used to test two alternative models of adolescent substance use onset and examine preventative intervention on adolescent substance use (Graham et al., 1991). The first model tested proposes that alcohol is the first substance used, then cigarettes, then first drunkenness, and then more intense use of cigarettes, alcohol and marijuana. The second model tested proposes that the first substance used is either cigarettes or alcohol, then the alternate substance, then drunkenness, and then advanced use (Kendel \& Yamaguchi, 1985). Goodness-of-fit for Model 1 was $G^{2}(220)=315.366$ and for Model $2 G^{2}(210)=208.948$. The models can be directly compared by subtracting $G^{2}$ for Model 1 from Model 2 since Model 1 is nested within Model 2. The degrees of freedom are also obtained by subtraction. Results indicate that Model 2 provides a significantly better fit than Model 1 $G^{2}(10)=106.418, \mathrm{p}<.0001$.

The study also examined the effectiveness of a school based substance use prevention program. Results indicate that those seventh graders who received a normative education curriculum had a significantly better outcome than those seventh graders who did not. Better outcome was marked by no transition to a higher use latent status or transition into a lower use latent status (Graham et al., 1991).

LTA has also been used to test three models for examining math skills acquisition, using a cohort of 1500 students in their sophomore year and beyond (Rock \& Pollack, 1987). Participants' math skills were tested using four testlets, each with five items designed to measure a particular math skill. If four of the five 
items were correct then the testlet was passed. The four testlets correspond to the five latent statuses: 1) no skill, 2) single operations on whole numbers, 3) single operations and powers and roots, decimals and fractions, 4) single operations, powers and roots, and low level algebra, and 5) single operations, powers and roots, lowlevel algebra and low-level geometry, algebra with word problems.

Model A proposed learning without unlearning between sophomore and senior year, $G^{2}=143.52(\mathrm{df}=221, \mathrm{p}=.999$, AIC $=211.52)$. Model B proposed learning and unlearning between sophomore and senior year, $G^{2}=137.31(\mathrm{df}=211, \mathrm{p}=.999$, AIC $=225.31$ ). And Model $\mathrm{C}$ proposed that neither learning nor unlearning takes place, $G^{2}=283.50(\mathrm{df}=231, \mathrm{P}=.011, \mathrm{AIC}=331.50)$. The results indicate that Model $\mathrm{C}$ has a significantly worse fit than Model A and Model B. By examining the $G^{2}$ difference $=6.21(\mathrm{df}=10, \mathrm{p}=.791)$ we see that Model A provides a satisfactory fit.

This study will examine movement among the stages of change for smoking cessation using a sample of reactively recruited self-change smokers, by examining adjacent panels in the longitudindal design. The purpose of this secondary analysis is to determine the pattern of the values in the transition probability matrix. 
Method

\section{Sample}

The sample consisted of 545 smokers and former smokers recruited in response to newspaper ads and articles in Rhode Island and Texas. The mean $( \pm$ SD) age of the sample was 39.7 (12.0) years, and $94 \%$ had at least graduated from high school. Of the sample, $68 \%$ were female, $58.5 \%$ were married, $94.9 \%$ were white, $2.6 \%$ were black and $2.7 \%$ were other races. Subjects were assessed five times over a two year period with measurement intervals of six months. The stages of change algorithm was part of a larger questionnaire battery. In this study the stages of change were still being developed and therefore have slightly different characteristics from present definitions. Subjects selected one of five statements that best described their current status.

Precontemplators are current smokers that have not tried to quit in the past year and have no plans to quit in the next year $(n=78)$. Contemplators are smokers that had not tried to quit in the past year and are seriously thinking about quitting in the next year $(n=243)$. The action stage is characterized by abstinence from cigarettes for less than six months $(n=80)$, and maintenance is characterized by abstinence from smoking for more than six months $(n=144)$. The preparation stage was not measured in this study. Those participants who were identified as relapsers were included in the contemplation stage. Relapsers appear similar to contemplators on other measures associated with the transtheoretical model (Prochaska et al., 199i). 


\section{Method of Analysis}

LTA will be used to specify a model that best explains movement between the stages and to examine transitions between the stages. Transitions between each of the time periods will be examined as a series of first order models (ie. between time 1 and time 2 , between time 2 and time 3 ). Therefore, no gamma parameters need to be estimated.

There is one manifest variable, or indicator, of latent status. The item has four response categories; 1) precontemplation (PC), 2) contemplation (C), 3) action (A) and 4) maintenance (M). One transition probability matrix will be estimated for each of the first order models. The rho matrix holds the parameter estimates for the probability of a particular response to the measured variable at each occasion of measurement. Only one rho matrix is required to start the parameter estimation. The program uses the same starting values for all times. One delta matrix will be estimated to represent the proportion of the population in each latent status for each time period.

Several alternative models will be tested and compared. Model I proposes

only one stage forward movement among the four latent statuses. Figure 1 illustrates Model I.

Model II proposes both forward and backward movement one stage only. Figure 2 illustrates Model II. 


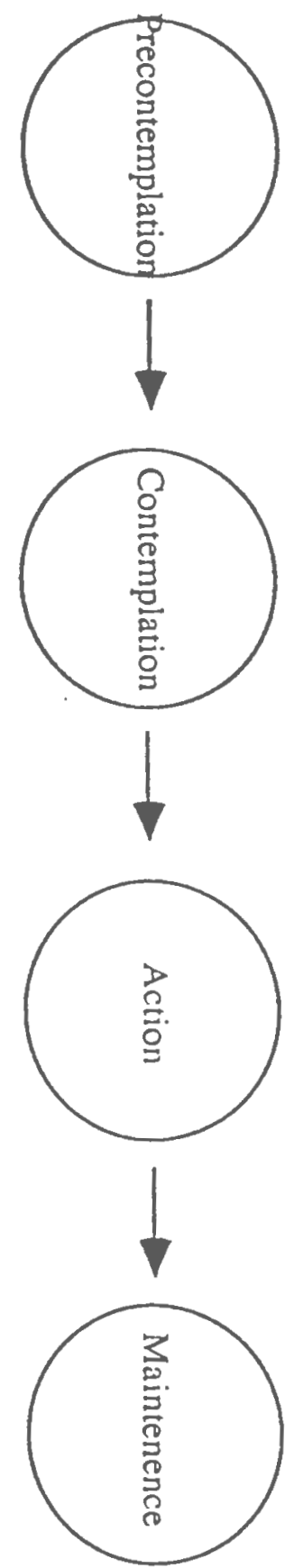

Figure 1. Model I: One stage forward movement only. 

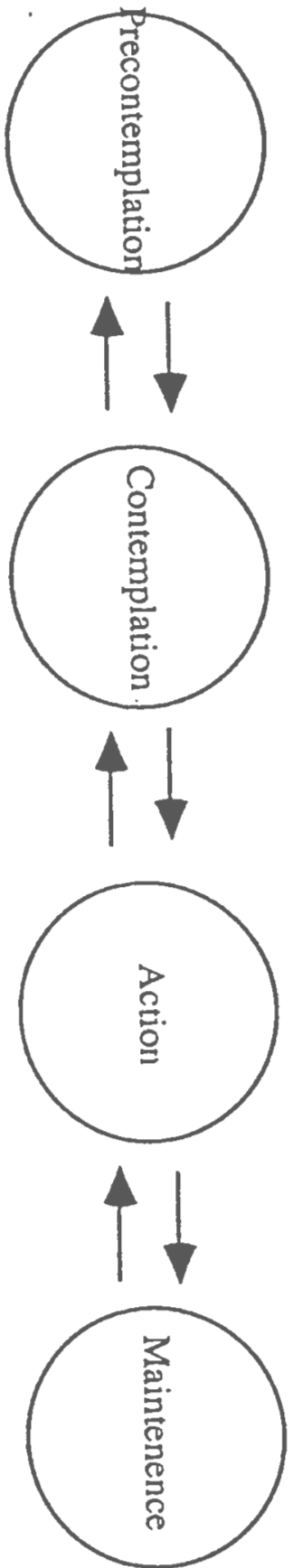

Figure 2. Model II: One stage forward and backward movement. 
Model III proposes that movement among the stages is both one stage forward and backward and two stage forward movement is permitted. Figure 3 illustrates Model III.

The rho parameter estimates in this model require a small discussion since there is only one item indicating latent status. Latent status membership, in this case, is determined by which of the four statements that a subject uses to describe their smoking status. Consequently, the probability of a particular response category being selected is directly extended to the probability of selection of latent status. The implications for this analyses is that there will be no true measurement parameters since there is no measurement error. The starting values for the rho parameters are as follows:

\begin{tabular}{|c|c|c|c|c|c|}
\hline & $\begin{array}{l}\text { Response } \\
\text { category } 1\end{array}$ & $\begin{array}{l}\text { Response } \\
\text { category } 2\end{array}$ & $\begin{array}{l}\text { Response } \\
\text { category } 3\end{array}$ & \multicolumn{2}{|c|}{$\begin{array}{l}\text { Response } \\
\text { category } 4\end{array}$} \\
\hline & $\begin{array}{ll}\mathrm{PC} & 1.0\end{array}$ & $\begin{array}{ll}\mathrm{PC} & 0\end{array}$ & $\begin{array}{ll}\mathrm{PC} & 0\end{array}$ & PC & 0 \\
\hline [6] & $\underline{C}$ & 1.0 & $\underline{\mathrm{C}}$ & $\underline{\mathrm{C}}$ & 0 \\
\hline & $\underline{\mathrm{A}}$ & $\underline{\mathrm{A}}$ & 1.0 & $\underline{\mathrm{A}}$ & 0 \\
\hline & $\underline{\mathrm{M}}$ & $\underline{\mathbf{M}}$ & $\underline{\mathbf{M}}$ & $\underline{\mathbf{M}}$ & 1.0 \\
\hline
\end{tabular}

The delta parameter estimates will indicate the growth or decline in stage membership. Since the sample which these estimates are based on is a nonrepresentative sample they will be interpreted cautiously.

As suggested by Collins, Wugalter and Rousculp (1992) a convergence criterion of .00001 will be used. The number of unique response patterns for time 1 to time 2 is 13 , time 2 to time 3 is 13 , time 3 to time 4 is 13 , and time 4 to time 5 is 14. is 108 . 


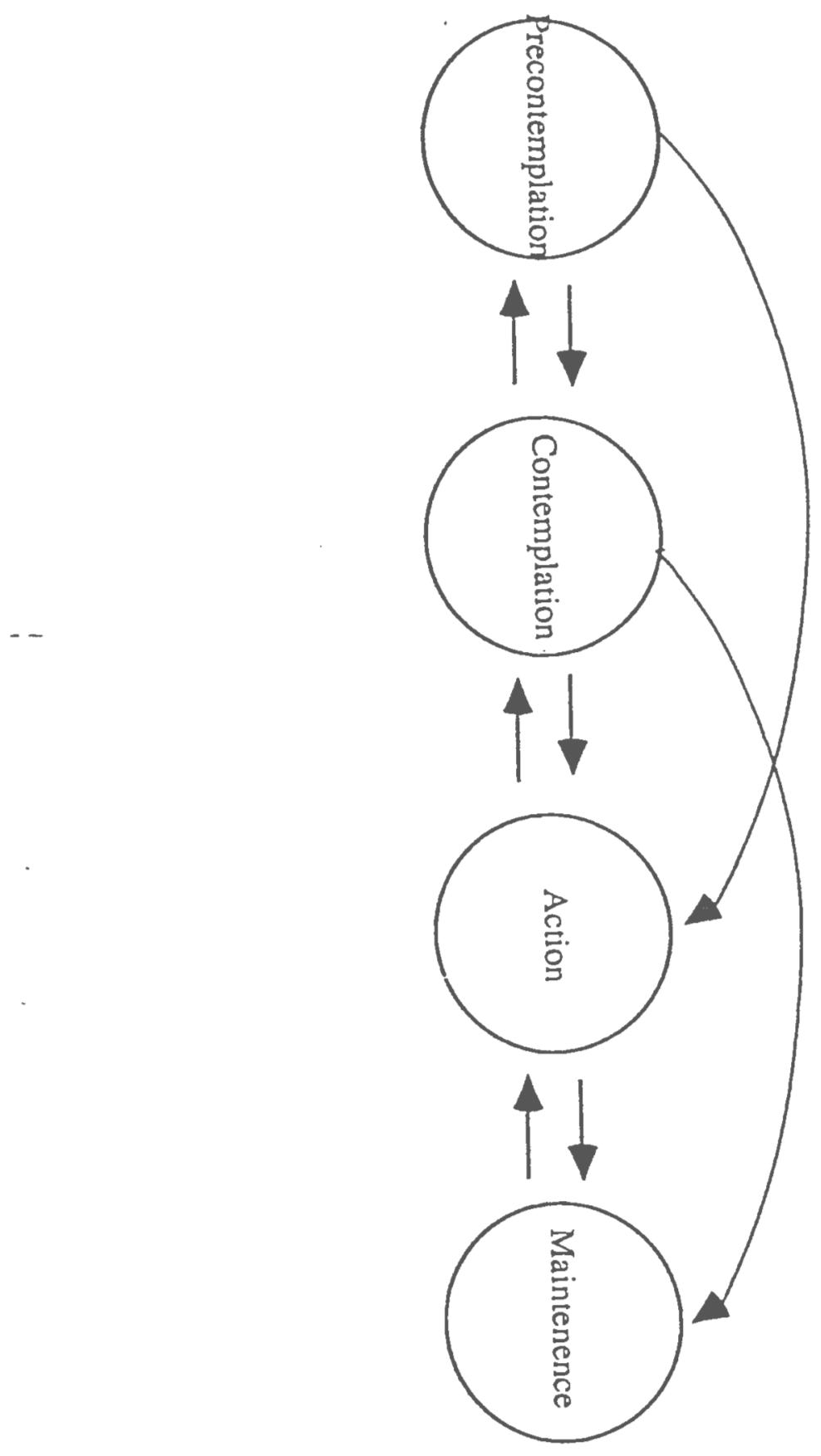

Figure 3. One stage forward and backward movement and two stage forward movement. 


\section{Analyses Interpretation}

The LTA output will provide an iterative history of G-squared as well as the final G-squared value and degrees of freedom. The three models will be compared for overall fit using G-squared. While providing an index of model fit is a strength of LTA, an additional focus of this study will be the individual parameters estimated.

The model that proposes only forward movement (Model I) is not expected to represent the data well. Model II and Model III are predicted to have better fit. Model II and Model III will be compared directly by the G-squared difference test of significance. It is predicted that the additional paths specified in Model III which represent two stage progression will be essential to represent the data.

The transition probability matrices will be examined. It is expected that the probability for transition to adjacent stages will be higher than non-adjacent stages. This expectation is consistent with the transtheoretical model which predicts that people move through a sequence of small changes, or stages, in their efforts to change. For example, the probability of a precontemplator transitioning to contemplation will be higher than the probability of transitioning to action or maintenance. Also, the probability of a contemplator transitioning to precontemplation or action will be higher than the probability of transitioning to maintenance. The tau matrix will have higher probability values immediately above and below the diagonal than the far off-diagonal values.

It is also predicted that the probability of forward movement among the stages will be higher than the probability of backward movement. This is consistent with the 
transtheoretical model that posits that there is a cyclical pattern to how people change. It is expected that progression through the stages is more probable than regression, and therefore the values above the diagonal of the matrix are expected to be higher than those below the diagonal.

Results

\section{First Order Models}

Time 1 to Time 2

Overall model fit for the three models is carried out by comparing $G^{2}$. For model I $\mathrm{G}^{2}(12)=3667.863$. For model II $\mathrm{G}^{2}(9)=534.918$, and for Model III, $\mathrm{G}^{2}(7)=284.350$. Model I obviously results in a significantly worse fit than either Model II or Model III. The $\mathrm{G}^{2}$ for Model I is substantially larger.

The remaining two models may be compared directly because Model $\mathrm{II}$ is nested in Model III. That is, Model II is a special case of Model III with certain parameters fixed at zero. The comparison can be made directly by subtracting the $\mathrm{G}^{2}$ for the more restrictive model, Model II, from the more general model, Model III. The degrees of freedom for the resulting $G^{2}$ are also obtained by subtraction. $G^{2}$. difference is 250.568 with 2 degrees of freedom, $\underline{p}<.001$. Assuming the $G^{2}$ difference is distributed as chi-square, the more restrictive model presents a significant decrement in model fit compared with the more general model. Model III provides better fit indicating that two stage progression is a necessary part of the model. 


\section{Parameter Estimates for Model III}

Probabilities of latent status membership at each occasion of measurement. . These parameters represent the proportion of the population in each of the five latent statuses at time 1 and time 2 . Table 1 shows that $42.8 \%$ of the subjects were in the contemplation stage at time 1 and only $41.8 \%$ of the subjects were in that stage at time 2.

There was a slight decline in contemplation stage membership from time 1 to time 2. The precontemplation stage had a slight increase in membership (15.4\% at time 1 and $15.7 \%$ at time 2). The proportion of subjects in action decreased substantially from $15.9 \%$ at time 1 to $7.5 \%$ at time 2 . However, proportion of subjects in maintenance increased substantially from $26 \%$ to $35 \%$.

Transition Probabilities. The transition probability matrix estimated for Model III is shown in Table 2. Several important findings are evident by examining the transition probability matrix. Figure 4 illustrates the transition probabilities paths for Model III. First, both forward and backward movement exists indicating that movement among the stages in not linear forward movement. Second, it was hypothesized earlier that the probability of forward movement would be greater than backward movement. This is true in the case of the those subjects who were in action at time 1. The probability of transitioning forward is greater. The percentage of subjects who transitioned forward to maintenance was $54.3 \%$, greater than those subjects who remained in action (17.4\%) and those who regressed to contemplation $(28.3 \%)$. 
Table 1

Delta Parameter Estimates, Probabilities of Latent Status Membership, for Model III

Time

\begin{tabular}{lccccc}
\cline { 2 - 6 } Stage & 1 & 2 & 3 & 4 & 5 \\
\hline Precontemplation & .154 & .157 & .185 & .104 & .104 \\
Contemplation & .428 & .418 & .330 & .375 & .331 \\
Action & .159 & .075 & .101 & .105 & .121 \\
Maintenance & .260 & .350 & .384 & .416 & .444 \\
\hline
\end{tabular}


Table 2

Tau Parameter Estimates, Probabilities of Latent Status Transitions, for Model III

Part I. Time 1 to Time 2

Stage Time 2

Stage Time $1 \quad$ Precontemplation Contemplation Action Maintenance

$\begin{array}{lllll}\text { Precontemplation } & .674 & .258 & .067 & .0 \\ \text { Contemplation } & .124 & .780 & .069 & .027 \\ \text { Action } & .0 & .283 & .174 & .543 \\ \text { Maintenance } & .0 & .0 & .027 & .973\end{array}$

Part II. Time 2 to Time 3

Stage Time 3

Stage Time 2 Precontemplation Contemplation Action Maintenance

$\begin{array}{lllll}\text { Precontemplation } & .658 & .231 & .111 & .0 \\ \text { Contemplation } & .196 & .654 & .108 & .042 \\ \text { Action } & .0 & .279 & .180 & .541 \\ \text { Maintenance } & .0 & .0 & .069 & .931\end{array}$

continued 
(Table 2 continued)

Part III. Time 3 to Time 4

Stage Time 4

Stage Time $3 \quad$ Precontemplation Contemplation Action Maintenance

\begin{tabular}{lllll}
\hline Precontemplation & .421 & .474 & .105 & .0 \\
Contemplation & .081 & .750 & .136 & .034 \\
Action & .0 & .391 & .217 & .391 \\
Maintenance & .0 & .0 & .048 & .952 \\
& & & & \\
\hline \hline
\end{tabular}

Part IV. Time 4 to Time 5

Stage Time 5

Stage Time $4 \quad$ Precontemplation Contemplation Action Maintenance

\begin{tabular}{lcccc}
\hline Precontemplation & .511 & .341 & .148 & .0 \\
Contemplation & .136 & .682 & .139 & .043 \\
Action & .0 & .381 & .286 & .333 \\
Maintenance & .0 & .0 & .056 & .944 \\
& & & & \\
\hline
\end{tabular}

Note. A value of .0 indicates that the parameter was fixed at zero; .000 indicates the value was estimated at zero. 


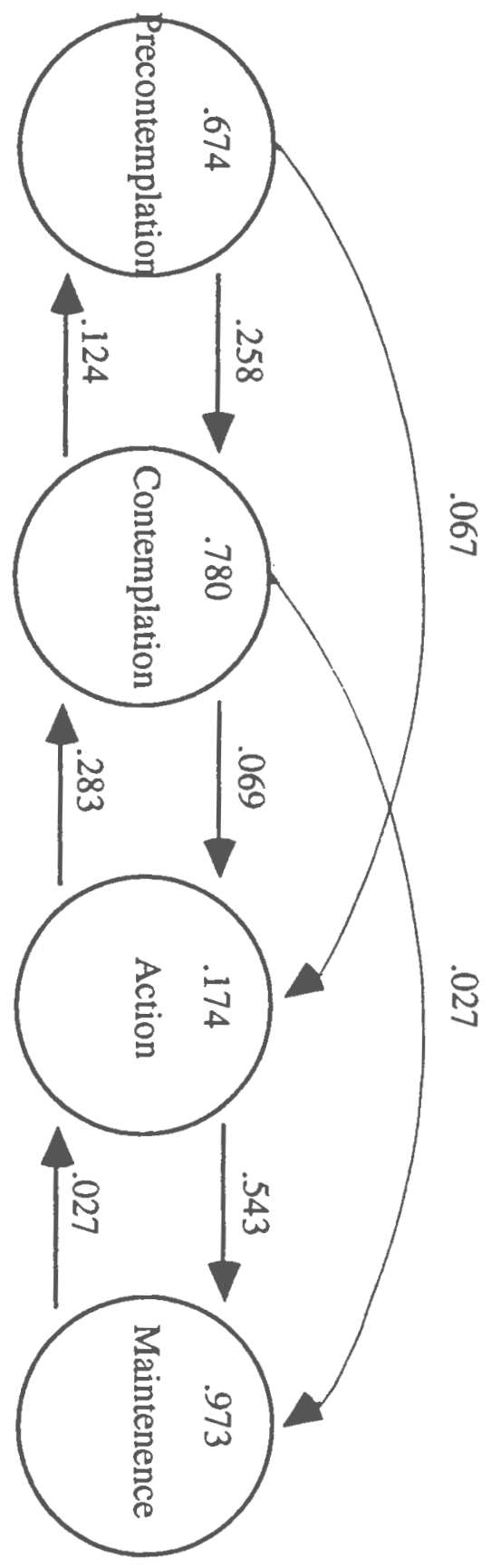

Figure 4. Tau parameter estimates for Model III time 1 to 2 . 
Third, it is interesting to note that although the probability of forward movement being greater was not true for subjects in the contemplation stage at time 1 , these subjects had very little movement overall. For contemplators the probability of transitioning out of contemplation was only .220.

Fourth, for three of the latent statuses, precontemplation, contemplation, and maintenance, the probability of remaining in the same latent status at both time 1 and time 2 was greater than the probability of moving to all other stages combined. For those subjects who began in precontemplation $67.4 \%$ remained in precontemplation, only $25.8 \%$ moved to contemplation and a smaller $6.7 \%$ moved all the way to action. For contemplators at time $178.0 \%$ remained in contemplation at time 2, $6.9 \%$ transitioned to action, $2.7 \%$ transitioned to maintenance, and $12.4 \%$ regressed to precontemplation. Almost all maintainers at time 1 remained in maintenance, $97.3 \%$. Very few maintainers, $2.7 \%$, regressed to action.

Fifth, the probability of transition to adjacent stages was greater than nonadjacent stages. Only $6.7 \%$ of precontemplators at time 1 transitioned to the nonadjacent action stage while $25.8 \%$ transitioned to the adjacent contemplation stage. A small $2.7 \%$ of contemplators at time 1 transitioned to the nonadjacent maintenance stage while $19.3 \%$ transitioned to either action or precontemplation.

Measurement parameters. As noted earlier, since, in this case, latent status membership is determined by which of the four responses a subject chooses to describe their smoking behavior three of the parameters estimated will be at zero. For example, the probability that someone in the precontemplation stage will choose 
the first response category is 1.0 , and that someone in the contemplation stage will choose the second response category is 1.0. This was presented in equation [6]. Time 2 to Time 3

For the three models overall model fit indices indicate that Model I does not represent the data well $\mathrm{G}^{2}(12)=4312.484$. For Model $\amalg \mathrm{G}^{2}(9)=877.962$, and for Model III $\mathrm{G}^{2}(7)=703.979$.

Model II and Model III can be compared by evaluating $\mathrm{G}^{2}$ difference. Assuming the $\mathrm{G}^{2}$ difference 173.983 with 2 degrees of freedom is distributed as chisquare Model II presents a significant decrement in model fit, $\mathrm{p}<.001$. The more general Model III provides a better fit of the data from time 2 to time 3.

\section{Parameter Estimates for Model III}

Probabilities of latent status membership at each occasion of measurement. The proportion of the population in each of the four latent statuses at time 2 and time 3 are represented by these parameters. Table 1 shows $7.5 \%$ of the subjects were in action at time 2 and a higher proportion, $10.1 \%$, were in action at time 3 . The proportion of subjects in action increased, while contemplation experienced a decline in stage membership (41.8\% at time 2 and $33.0 \%$ at time 3 ). Precontemplation and maintenance stages both had increased membership at time 3 .

Transition Probabilities. The transition probability matrix estimated for Model III is shown in Table 2. Several important observations are evident by examining the transition probability matrix. Figure 5 illustrates the transition probabilities paths for Model III. First, both forward and backward movement exists indicating that 


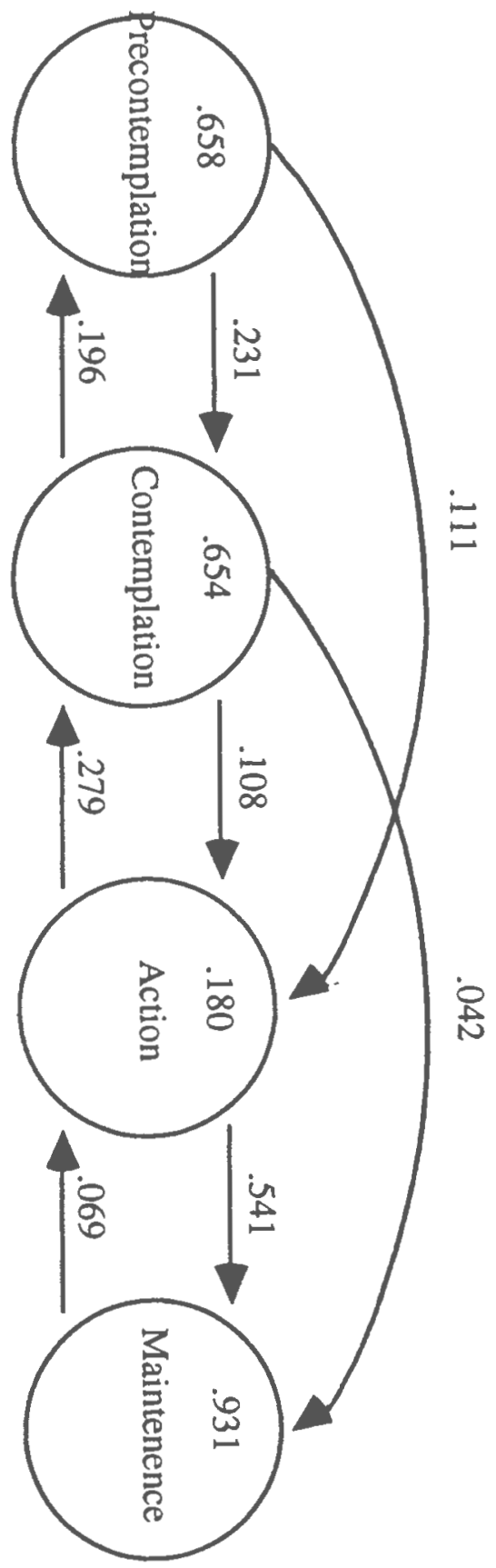

Figure 5. Tau parameter estimates for Model III time 2 to 3. 
movement among the stages in not linear forward movement. Second, it was hypothesized earlier that the probability of forward movement would be greater than backward movement. This is true in the case of the those subjects who were in action at time 2. The percentage of subjects who transitioned forward to maintenance was $54.1 \%$, greater than those subjects who remained in action (18.0\%) and those who regressed to contemplation (27.9\%). Third, it is interesting to note that although the probability of forward movement being greater was not true for subjects in the contemplation stage at time 2 , these subjects had very little movement overall.

Fourth, for three of the latent statuses, precontemplation, contemplation, and maintenance, the probability of remaining in the same latent status at both time 2 and time 3 was greater than the probability of moving to all other stages combined. For those subjects who began in precontemplation $65.8 \%$ remained in precontemplation, only $23.1 \%$ moved to contemplation and a smaller $11.1 \%$ moved all the way to . action. For contemplators at time $2,65.4 \%$ remained in contemplation at time 3, $4.2 \%$ transitioned to maintenance, and $19.6 \%$ regressed to precontemplation. A high percent of maintainers at time 2 remained in maintenance, $93.1 \%$. Few maintainers, $6.9 \%$, regressed to action.

Fifth, the probability of transition to adjacent stages was greater than nonadjacent stages. Only $11.1 \%$ of precontemplators at time 2 transitioned to the nonadjacent action stage while $23.1 \%$ transitioned to the adjacent contemplation stage. A small $4.2 \%$ of contemplators at time 2 transitioned to the nonadjacent maintenance stage while $10.8 \%$ transitioned to action. 


\section{Time 3 to Time 4}

Overall model fit for the three models is carried out by comparing $\mathrm{G}^{2}$. For Model I $\mathrm{G}^{2}(12)=2525.779$. For model II $\mathrm{G}^{2}(9)=930.769$, and for Model III, $\mathrm{G}^{2}(7)=457.343$. Model I obviously results in a significantly worse fit than either Model II or Model III. The $\mathrm{G}^{2}$ for Model I is substantially larger.

The remaining two models may be compared directly because Model $\Pi$ is considered a nested model of Model III. That is, Model II is a special case of Model III with certain parameters fixed at zero. The comparison can be made directly by subtracting the $\mathrm{G}^{2}$ for the more restrictive model, Model II, from the more general model, Model III. The degrees of freedom for the resulting $\mathrm{G}^{2}$ are also obtained by subtraction. $\mathrm{G}^{2}$ difference is 473.426 with 2 degrees of freedom, $\mathrm{p}<.001$. Assuming the $\mathrm{G}^{2}$ difference is distributed as chi-square, the more restrictive model presents a significant decrement in model fit compared with the more general model. In other words, Model III provides better fit indicating that two stage progression is a necessary part of the model.

\section{Parameter Estimates for Model III}

Probabilities of latent status membership at each occasion of measurement. These parameters represent the proportion of the population in each of the five latent statuses at time 3 and time 4 . Table 1 shows that $18.5 \%$ of the subjects were in the precontemplation stage at time 3 and only $10.4 \%$ of the subjects were in that stage at time 4. Precontemplation was the only stage that experienced a decrease in stage membership. For all other stages the proportion of subjects at time 4 was greater 
than at time 3 .

Transition Probabilities. The transition probability matrix estimated for Model III is shown in Table 2. Several important observations are evident by examining the transition probability matrix. Figure 6 illustrates the transition probabilities paths for Model III. First, both forward and backward movement exists indicating that movement among the stages in not linear forward movement. Second, it was hypothesized earlier that the probability of forward movement would be greater than backward movement. This is true in the case of the those subjects who were in contemplation at time 3. The percentage of subjects who transitioned forward to action was $13.6 \%$ and $3.4 \%$ transitioned forward to maintenance. Seventy-five percent remained in contemplation and only $8.1 \%$ regressed to precontemplation. For subjects who were in action at time 3 there was equal probability that they would progress to maintenance or regress to contemplation $(.391)$.

Third, for two of the latent statuses, contemplation and maintenance, the probability of remaining in the same latent status at both time 3 and time 4 was greater than the probability of moving to all other stages combined. For those subjects who began in contemplation at time $3,75 \%$ remained in contemplation at time $4,13.6 \%$ transitioned to action, $3.4 \%$ transitioned to maintenance, and $8.1 \%$ regressed to precontemplation. Almost all maintainers at time 3 remained in maintenance, $95.2 \%$. Very few maintainers, $4.8 \%$, regressed to action.

Fifth, the probability of transition to adjacent stages was greater than nonadjacent stages. Only $10.5 \%$ of precontemplators at time 3 transitioned to the 


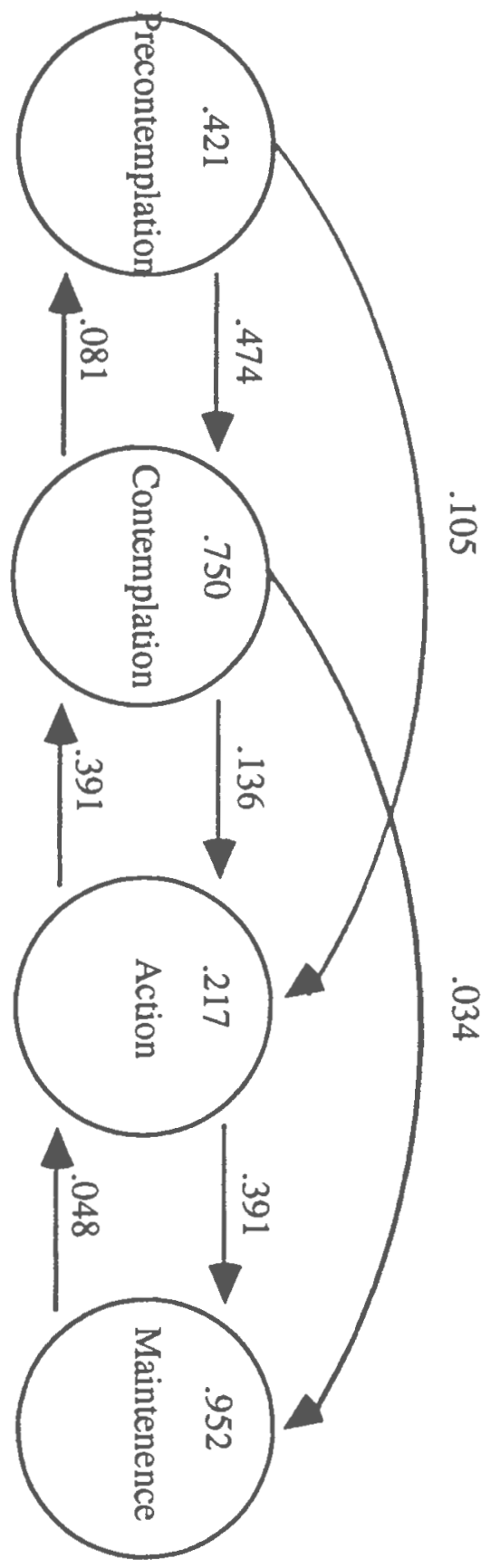

Figure 6. Tau parameter estimates for Model III time 3 to 4 . 
nonadjacent action stage while $47.4 \%$ transitioned to the adjacent contemplation stage. A small $3.4 \%$ of contemplators at time 3 transitioned to the nonadjacent maintenance stage while $13.6 \%$ transitioned to action.

\section{Time 4 to Time 5}

For the three models overall model fit indices indicate that Model I does not represent the data well $\mathrm{G}^{2}(12)=3927.822$. For Model II $\mathrm{G}^{2}(9)=978.018$, and for Model III $\mathrm{G}^{2}(7)=564.485$.

Model II and Model III can be compared by evaluating $\mathrm{G}^{2}$ difference. Assuming the $\mathrm{G}^{2}$ difference 413.533 with 2 degrees of freedom is distributed as chisquare Model II presents a significant decrement in model fit, $\mathbf{p}<.001$. The more general Model III provides a better fit of the data from time 4 to time 5 .

\section{Parameter Estimates for Model III}

Probabilities of latent status membership at each occasion of measurement. The proportion of the population in each of the four latent statuses at time 4 and time 5 are represented by these parameters. Table 1 shows $10.4 \%$ of the subjects were in precontemplation at time 4 and $10.4 \%$, were in precontemplation at time 5 indicating that there was no change in the proportion of subjects in precontemplation membership. The proportion of subjects in contemplation decreased from 37.5 at time 4 to $33.1 \%$ at time 5. Action and maintenance stages both had increased membership at time 5 .

Transition Probabilities. The transition probability matrix estimated for Model III is shown in Table 2. Several interesting findings are evident by examining the 
transition probability matrix. Figure 7 presents the transition probabilities paths for Model III. First, both forward and backward movement exists indicating that movement among the stages in not linear forward movement. Second, it was hypothesized earlier that the probability of forward movement would be greater than backward movement. This is true for those subjects who were in contemplation at time 4. For contemplators the percentage of subjects who transitioned forward to either and action or maintenance was $18.2 \%$, greater than those subjects who regressed to precontemplation $(13.6 \%)$.

Third, for three of the latent statuses, precontemplation, contemplation, and maintenance, the probability of remaining in the same latent status at both time 4 and time 5 was greater than the probability of moving to all other stages combined. For those subjects who began in precontemplation $51.1 \%$ remained in precontemplation, only $34.1 \%$ moved to contemplation and a smaller $14.8 \%$ moved all the way to action. For contemplators at time $4,68.2 \%$ remained in contemplation at time 5, $4.3 \%$ transitioned to maintenance, and $13.6 \%$ regressed to precontemplation. A high percent of maintainers at time 4 remained in maintenance, $94.4 \%$. Few maintainers, $5.6 \%$, regressed to action at time 5 .

Fifth, the probability of transition to adjacent stages was greater than nonadjacent stages. Only $14.8 \%$ of precontemplators at time 4 transitioned to the nonadjacent action stage while $34.1 \%$ transitioned to the adjacent contemplation stage. A small $4.3 \%$ of contemplators at time 4 transitioned to the nonadjacent maintenance stage while $13.9 \%$ transitioned to action. 


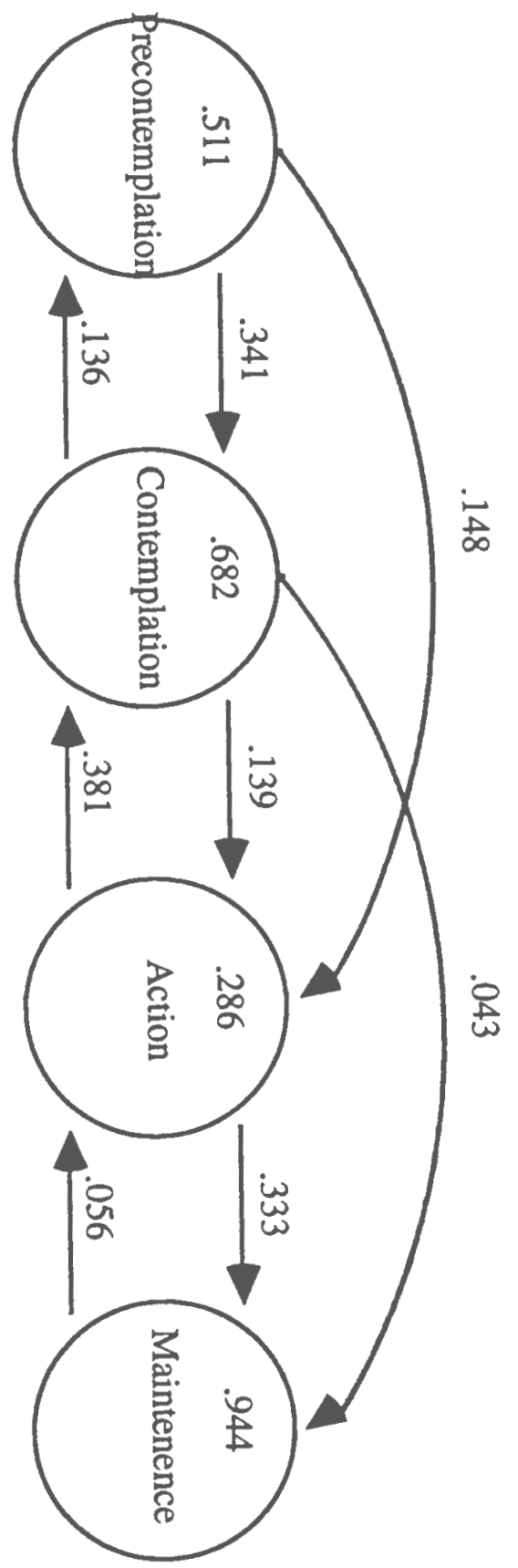

Figure 7. Tau parameter estimates for Model III time 4 to 5 . 


\section{Discussion}

This study was an application of latent transition analysis to the stages of change for smoking cessation. LTA was used to compare three specified models of movement among the four stages of change over five measurement occasions. The most restrictive model allowed only one stage movement, a second model also allowed only one stage movement but in both forward and backward directions, and the most general model allowed forward and backward movement and two stage forward progression. Model fit was evaluated with goodness-of-fit chi-square tests.

The major findings of this study involve: (1) identification of an appropriate model to describe the patterns of movement among the stages for naturalistic smoking cessation based on a reactively recruited sample, (2) estimation of individual transition probability patterns, (3) stability of stage membership, and (4) a statistical alternative to traditional outcome measures.

An important contribution of this technique is testing of alternate models. The results reported here indicate that of the three models tested, the one that best fit the stages of change data for smoking cessation was the more general model that allowed forward and backward movement and two stage progression. Both progression and regression are necessary to describe how people change.

Model III shows that smokers transition from precontemplation to action. These subjects were not planning to quit smoking yet did within six months of assessment. Model III also indicates smokers transition from contemplation to maintenance, indicating two stage progression to maintenance. As this movement 
appears to not be theoretically consistent with the transtheoretical model it requires a small discussion. The action stage is the period where smokers are making overt changes in their behavior, i.e. quitting smoking, and lasts for six months.

A small portion of smokers thinking of changing in the near future progress all the way to maintenance within six months. This may be an artifact of the author's original data preparation. Those subjects who were identified as relapsers were not assigned stage membership at time of assessment. These smokers were included in the contemplation stage by the author since they are most similar to contemplators on other measures. It may be that subjects who appeared to skip action were previously in action or maintenance and were smoking at the time of assessment. Therefore the quit attempt may have began at least six months prior, but the subject had lapsed to smoking, temporarily, at time of assessment. This distinction is important since it · indicates that these subjects were not consistently abstinent from smoking cigarettes for a six month period. Also subjects' may have been outside of a six month period. Future applications of LTA to the stages of change should include the actual staging for all subjects, including relapsers.

Several consistent and strong observations about the pattern of transition between stages were found across the first order models. Progression between stages is more likely than regression. This significant result has broad implications. For smokers who are planning to quit in the near future (contemplators) there is a greater likelihood that they will quit smoking than regressing to precontemplation. This is especially meaningful when developing interventions for smokers. Interventions for 
contemplators can be targeted at strengthening this probability.

Those former smokers who had quit within six months (action) appear to transition quickly out of action. The membership in the action stage is not very stable (as will be discussed later). However, the likelihood that those in action will continue to be abstinent for more than six months was greater than the probability of returning to smoking.

Although the movement between the stages is very dynamic, results presented here indicate that smokers and former smokers are more likely to transition to the nearest stage. Two stage progression is not as probable as moving to adjacent stages. This observation also has broad implications particularly for intervention. Only a very small proportion moved two stages. Targeting stage matched interventions at transitioning smokers to one stage forward would capture a very high proportion of smokers. This result indicates that there is a systematic characteristic to the way people change.

The transition probabilities also revealed stability characteristics of the stages. The stability of stage membership was the highest for the maintenance stage. Former smokers who have been abstinent for more than six months are more likely to remain in maintenance than move to all other stages combined. The contemplation stage also appear to be quite stable although not as stable as maintenance. The probability of remaining in contemplation is greater than .50 .

The action stage appears to be the least stable. Former smokers who have been abstinent for less than six months appear to be least likely to remain in the same 
stage. Although the probability of becoming a maintainer is higher than becoming a contemplator, the instability of the action stage is indicative of the risk for returning to smoking cigarettes.

The delta parameters show the unconditional probability of latent status membership. Overall, the membership in precontemplation and contemplation show a steady decline over time while the action and maintenance stages show steady increase in membership. The manner in which the proportions change is consistent with results of the transition probabilities. A greater number of subjects were engaged in attempts to quit smoking hence the decline in precontemplation and contemplation stage memberships. The delta parameter estimates should be interpreted cautiously, however, because they were estimated from a non-represenative sample.

LTA is an important alternative to traditional outcome measures. Outcome indicators and techniques for examining outcome tend to be unsophisticated, mostly tests of proportions. The application of LTA to the stages of change has several strengths and capabilities that traditional outcome techniques do not. First, it allows for specification and testing of alternative models of ordered categorical data. This is an important contribution to the transtheoretical model. The movement among the stages had been hypothesized to be cyclical. LTA allowed us to test which movement paths, in both forward and backward directions, represent how people progress and regress through the stages of change. Testing of models goes beyond just descriptive value. LTA can be used as a confirmatory analysis for specified models. The first order models both described the process of change and also confirmed the model 
specified.

Second, the stages were used as the outcome variable. Previously, categorical data, such as the stages, was not a strong measure for outcome. Even Latent Class Theory is not sensitive to movement among latent categorical variables. Movement among stage membership is viewed as the dependent outcome variable in LTA. The stages of change model is sensitive to the whole range of changes as people modify health behaviors, even before overt behavior changes are attempted (PC and C), and therefore particularly appropriate for LTA.

Third, LTA indicates the error in measurement. Future applications to the stages of change model may compare different measurement techniques and evaluate the measurement error associated with each.

This application of LTA to the stages of change is different from previous applications of LTA in several ways. First, most examples of LTA have only two and three occasions of measurement. This study had five occasions of measurement which allows us to examine and compare first order models. Multiple occasions of measurement allow for examination of several first order models where similar patterns of movement were replicated. Second, this is the first application of LTA. where the manifest indicators of latent status are polyotomous. Previous examples have used only dichotomous response categories. This study has four response categories. This extends the models specified beyond any previously tested.

This study is a limited application of LTA to the stages of change. Potential applcations of LTA can extend the models specified in this study. The addition of a 
latent class variables can contribute to the clinical implications of the stages of change. Group, or class membership, differences can be examined where the classes are the type of treatment received. LTA can compare several types of interventions and subsequent movement through the stages of change. It has been hypothesized that stage matched interventions may result in better outcome. The tau matrices can be examined to determine if different interventions have different transition probabilities.

In summary, the major contributions of this study involve the application of a new technique for ordered categorical data. A model for characterizing progression and regression among the stages of change for smoking cessation was identified. Transition probabilities among the stages were stronger for forward movement than backward movement, and for adjacent stage movement than nonadjacent stage movement. The maintenance stage had the greatest stability followed by contemplation and precontemplation. Continued applications of LTA to stage of change data are warranted. 


\section{References}

Abrams, D. B., Emmons, K. M., Linnan, L. \& Biener, L (In press). Smoking Cessation at the workplace: conceptual and practical considerations. in $\mathbf{R}$. Richmond (Ed.), Interventions for Smokers: An International Perspective. New York: Williams \& Wilkins Publishing Company.

Akaike, H. (1987). Factor analysis and the AIC. Psychometrika, 52, 317-332.

Bye, B. V. \& Schechter, E. S. (1986). A latent Markov model approach to the estimation of response errors in multiwave panel data. Journal of the American Statistical Association, 81, 375-380.

Clogg, C. C. \& Goodman, L. A. (1984). Latent structure analysis of a set of multidemensional contingency tables. Journal of the American Statistical Association, 79, 762-771.

Collins, L. M. \& Cliff, N. (1990). Using the longitudinal Guttman simplex as a basis for measuring growth. Psychological Bulletin 108, 128-134.

Collins, L. M. \& Wugalter, S. E. (1992). Latent class models for stage-sequential dynamic latent variables. Mutivariate Behavioral Research, 27, 131-137.

Collins, L. M, Wugalter, S. E. \& Rousculp, S. S. (1991). LTA User's Manual. Los Angeles: J.P. Guilford Laboratory of Quantitative Psychology, University of Southern California.

Dayton, C. M. \& Macready G. B. (1976). A Probabilistic model for validation of behavioral hierarchies. Psychometrika, 41, 189-204. 
Dempster, A. P., Laird, N. M., \& Rubin, D. B. (1977). Maximum likelihood from incomplete data via the EM algorithm. Journal of the Royal Statistical Society, $\underline{39}, 1-38$.

DiClemente, C. C. \&\& Prochaska, J. O. (1982). Self-change and therapy change of smoking behavior: A comparison of processes of change of cessation and maintenance. Addictive Behaviors, 7, 133-142.

DiClemente, C. C., Prochaska, J. O., Fairhurst, S. K., Velicer, W. F., Velasquez, M. M. \& Rossi, J. S. (1991). The process of smoking cessation: An analysis of precontemplation, contemplation, and preparation stages of change. Journal of Consulting and Clinical Psychology, 59, 295-304.

Embretson, S. E. (1991). Implications of a multidemensional latent trait model for measuring change. In L. M. Collins \& J. L. Horn (Eds.), Best Methods for Analysis of Change: Recent $\underline{\text { Advances, Unanswered Questions, Future }}$ Directions. Washington, D. C.: American Psychological Association, $762-771$.

Fisher, G. H. (1983). Some latent trait models for measuring change in qualitative observations. In Embretson, S. E. (Ed.) New Horizons in Testing. New York: Academic Press.

Graham, J. W., Collins, L. M., Wugalter, S. E., Chung, N. J., \& Hansen, N. B.(1991). Modeling transitions in latent stage-sequential processes; A substance use prevention example. Journal of Consulting and Clinical Psychology, $\underline{\text { 59, }}$ 48-57. 
Kohlberg, L. (1969). Stage and sequence: The cognitive-developmental approach to socialization. In D. A. Goslin (Ed.), Handbook of Socialization Theory and Research. Chicago: Rand McNally.

Kubler-Ross, E. (1975). Death: The Final Stage of Growth. Englewood Cliffs, NJ:Prentice-Hall.

Lazarfeld, P. F. \& Henry, N. W. (1968). Latent Structure Analysis. Boston: Houghton Mifflin.

McConnaughy, E. A., DiClemente, C. C., Prochaska, J. O., \& Velicer, W. F., (1989). Stages of change in psychotherapy: A follow-up report.

Psychotherapy, 26, 494-503.

McConnaughy, E. A., Prochaska, J. O., \& Velicer, W. F., (1983). Stages of change in psychotherapy: Measurement and sample profiles.

Psychotherapy:Theory, Research, and Practice, 20, 368-375.

Prochaska, J. O. \& Goldstein, M. (1991). The process of smoking cessation:

Implication for clinicians. Clinics in Chest Medicine, 12, 727-735.

Prochaska, J. O. \& DiClemente, C. C. (1983). Stages and processes of self-change of smoking: Toward and integrative model of change. Journal of Consulting and Clinical Psychology, 51 , $390-395$.

Prochaska, J. O. \& DiClemente, C. C. (1986). Toward a comprehensive model of change. In W.R. Miller \& N. Heather (Eds.), Treating Addictive Behaviors New York: Plenum.

Prochaska, J. O. \& DiClemente, C. C. (1992). Stages of change in the modification 
of problem behaviors. In M. Heursen, R. M. Eilser \& P. M. Miller (eds.), Progress in Behavior Modification. Sycamore, IL: Sycamore Press.

Prochaska, J. O., Velicer, W. F., DiClemente, C. C. \& Fava, J. (1988). Measuring processes of change: Applications to the cessation of smoking. Journal of Consulting and Clinical Psychology, 56, 520-528.

Prochaska, J. O., Velicer, W. F., Guadagnoli, E., \& Rossi, J. S. (1991). Patterns of change: Dynamic typology applied to smoking cessation. Multivariate Behavioral Research, 26, 83-107.

Rock, D. A. \& Pollack-Ohls, J. (1987). Measuring gains: $\underline{\text { A new look } \underline{\text { at }} \text { an old }}$ problem. Princeton: Educational Testing Service.

van de Pol, F.,\& de Leeuw, J. (1986). A latent Markov model to correct for measurement error. Sociological Methods and Research, $\underline{15}, 118-141$. van de Pol, F., Langeheine, R. (1989). Mover-stayer models, mixed Markov models and the EM algorithm; with an application to labour market data from the Netherlands Socio Economic Panel. In R. Coppi \& S. Bolasco (eds.), Multiway Data Analysis. North Holland: Amsterdam, pp. 485-495.

Velicer, W. F., DiClemente, C. C., Prochaska, J. O., \& Brandenburg, N. (1985).

Decisional Balance Measure for Assessing and Predicting Smoking Status. Journal of Personality and Social Psychology, 48 , 1279-1289.

Velicer, W. F., DiClemente, C. C., Rossi, J. S., \& Prochaska, J. O., (1990). Relapse situations and self-efficacy: An integrative model. Addictive Behaviors, 15, 271-283. 
Velicer, W. F., Prochaska, J. O., Rossi, J. S., \& Snow, M. G. (1992). Assessing Outcome in Smoking Cessation Studies. Psychological Bulletin.

Wiggins, L. M. (1973). Panel Analysis. Amsterdam: Elsevier. 


\section{Bibliography}

Abrams, D. B., Emmons, K. M., Linnan, L. \& Biener, L (In press). Smoking Cessation at the workplace: conceptual and pratical considerations. in $\mathbf{R}$. Richmond (Ed.), Interventions for Smokers: An International Perspective. New York: Williams \& Wilkins Publishing Company.

Akaike, H. (1987). Factor analysis and the AIC. Psychometrika, $\underline{52}, 317-332$.

Bye, B. V. \& Schechter, E. S. (1986). A latent Markov model approach to the estimation of response errors in multiwave panel data. Journal of the American Statistical Association, 81, 375-380.

Clogg, C. C. \& Goodman, L. A. (1984). Latent structure analysis of a set of multidemensional contingency tables. Journal of the American Statistical Association, 79, 762-771.

Collins, L. M. \& Cliff, N. (1990). Using the longitudinal Guttman simplex as a basis for measuring growth. Psychological Bulletin, 108, 128-134.

Collins, L. M. \& Wugalter, S. E. (1992). Latent class models for stage-sequential dynamic latent variables. Mutivariate Behavioral Research, 27, 131-137.

Collins, L. M, Wugalter, S. E. \& Rousculp, S. S. (1991). LTA User's Manual. Los Angeles: J.P. Guilford Laboratory of Quantitative Psychology, University of Southern California.

Dayton, C. M. \& Macready G. B. (1976). A Probabilistic model for validation of behavioral hierarchies. Psychometrika, 41, 189-204. 
Dempster, A. P., Laird, N. M., \& Rubin, D. B. (1977). Maximum likelihood from incomplete data via the EM algorithm. Journal of the Royal Statistical Society, $\underline{39}, 1-38$.

DiClemente, C. C.,\& Prochaska, J. O. (1982). Self-change and therapy change of smoking behavior: A comparison of processes of change of cessation and maintenance. Addictive Behaviors, $7,133-142$.

DiClemente, C. C., Prochaska, J. O., Fairhurst, S. K., Velicer, W. F., Velasquez, M. M. \& Rossi, J. S. (1991). The process of smoking cessation: An . analysis of precontemplation, contemplation, and preparation stages of change. Journal of Consulting and Clinical Psychology, 59, 295-304.

Embretson, S. E. (1991). Implications of a multidemensional latent trait model for measuring change. In L. M. Collins \& J. L. Horn (Eds.), Best $\underline{\text { Methods for }}$ Analysis of Change: Recent Advances, Unanswered Questions, Future Directions. Washington, D. C.: American Psychological Association, $762-771$.

Fisher, G. H. (1983). Some latent trait models for measuring change in qualitative observations. In Embretson, S. E. (Ed.) New Horizons in Testing. New York: Academic Press.

Graham, J. W., Collins, L. M., Wugalter, S. E., Chung, N. J., \& Hansen, N. B.(1991). Modeling transitions in latent stage-sequential processes; A substance use prevention example. Journal of Consulting and Clinical Psychology, 59, 48-57. 
Kohlberg, L. (1969). Stage and sequence: The cognitive-developmental approach to socialization. In D. A. Goslin (Ed.), Handbook of Socialization Theory and Research. Chicago: Rand McNally.

Kubler-Ross, E. (1975). Death: The Final Stage of Growth. Englewood Cliffs, NJ:Prentice-Hall.

Lazarfeld, P. F. \& Henry, N. W. (1968). Latent Structure Analysis. Boston: Houghton Mifflin.

McConnaughy, E. A., DiClemente, C. C., Prochaska, J. O., \& Velicer, W. F., (1989). Stages of change in psychotherapy: A follow-up report. Psychotherapy, 26, 494-503.

McConnaughy, E. A., Prochaska, J. O., \& Velicer, W. F., (1983). Stages of change in psychotherapy: Measurement and sample profiles.

Psychotherapy:Theory, Research, and Practice, 20, 368-375.

Prochaska, J. O. \& Goldstein, M. (1991). The process of smoking cessation:

Implication for clinicians. Clinics in Chest Medicine, 12, 727-735.

Prochaska, J. O. \& DiClemente, C. C. (1983). Stages and processes of self-change of smoking: Toward and integrative model of change. Journal of Consulting and Clinical Psychology, $\underline{51}, 390-395$.

Prochaska, J. O. \& DiClemente, C. C. (1986). Toward a comprehensive model of change. In W.R. Miller \& N. Heather (Eds.), Treating Addictive Behaviors New York: Plenum.

Prochaska, J. O. \& DiClemente, C. C. (1992). Stages of change in the modification 
of problem behaviors. In M. Heursen, R. M. Eilser \& P. M. Miller (eds.), Progress in Behavior Modification. Sycamore, IL: Sycamore Press. Prochaska, J. O., Velicer, W. F., DiClemente, C. C. \& Fava, J. (1988). Measuring processes of change: Applications to the cessation of smoking. Journal of Consulting and Clinical Psychology, 56, 520-528.

Prochaska, J. O., Velicer, W. F., Guadagnoli, E., \& Rossi, J. S. (1991). Patterns of change: Dynamic typology applied to smoking cessation. Multivariate Behavioral Research, 26, 83-107.

Rock, D. A. \& Pollack-Ohls, J. (1987). Measuring gains: $\underline{A} \underline{\text { new }} \underline{\text { look }}$ at an old problem. Princeton: Educational Testing Service.

van de Pol, F., \& de Leeuw, J. (1986). A latent Markov model to correct for measurement error. Sociological Methods and Research, $\underline{15}, 118-141$. van de Pol, F., Langeheine, R. (1989). Mover-stayer models, mixed Markov models and the EM algorithm; with an application to labour market data from the Netherlands Socio Economic Panel. In R. Coppi \& S. Bolasco (eds.), Multiway Data Analysis. North Holland: Amsterdam, pp. 485-495.

Velicer, W. F., DiClemente, C. C., Prochaska, J. O., \& Brandenburg, N. (1985):

Decisional Balance Measure for Assessing and Predicting Smoking Status. Journal of Personality and Social Psychology, $\underline{48}$, 1279-1289.

Velicer, W. F., DiClemente, C. C., Rossi, J. S., \& Prochaska, J. O., (1990). Relapse situations and self-efficacy: An integrative model. Addictive Behaviors, 15, 271-283. 
Velicer, W. F., Prochaska, J. O., Rossi, J. S., \& Snow, M. G. (1992). Assessing Outcome in Smoking Cessation Studies. Psychological Bulletin.

Wiggins, L. M. (1973). Panel Analysis. Amsterdam: Elsevier. 